\title{
Speciation Study of Heavy Metals in Soil within the Vicinity of a Metal Recycling Factory at Ile-Ife, Southwestern Nigeria \\ John AdekunleOyedeleOyekunle ${ }^{a *}$, AbolanleSaheedAdekunle ${ }^{b *}$, AderemiOkunolaOgunfowokan ${ }^{\mathrm{c}}$, LateefatMoyosoreDurosinmi ${ }^{\mathrm{d}}$, OlusolaAdelowotan ${ }^{\mathrm{e}}$, and Olugbenga Timothy Oyeku ${ }^{f}$
}

Department of Chemistry, ObafemiAwolowo University, Ile-Ife, Nigeria aoyekunle@oauife.edu.ng

bsadek2k@yahoo.com

caogunfow@oauife.edu.ng

dmdurosin@oauife.edung

emelroseshols@yahoo.com

fgbengaoyeku@yahoo.com

\begin{abstract}
A speciation study of $\mathrm{Al}, \mathrm{Cd}, \mathrm{Cu}, \mathrm{Mn}, \mathrm{Pb}$ and $\mathrm{Zn}$ in soil samples from a metal recycling factory in lle-Ife Osun State, Nigeria, was carried out in order to assess the heavy metal pollution impact of the industrial processes on the immediate environment. Surface soil dust samples collected within the vicinity of the factory were subjected to a five-stage sequential extraction process. Levels of heavy metals in each fraction were determined using Flame Atomic Absorption Spectrophotometer (FAAS). The overall mean values obtained for the metals in the fractions gave the range: $\mathrm{Al}(0.03 \pm$ 0.01 to $0.20 \pm 0.01 \mu \mathrm{g} / \mathrm{g}) ; \mathrm{Cd}(0.03 \pm 0.01$ to $0.23 \pm 0.02 \mu \mathrm{g} / \mathrm{g}) ; \mathrm{Cu}(2.93 \pm 0.02$ to $18.30 \pm 1.95 \mu \mathrm{g} / \mathrm{g}) ; \mathrm{Mn}(17.33 \pm 0.03$ to $91.68 \pm 2.90 \mu \mathrm{g} / \mathrm{g}) ; \mathrm{Pb}(0.03 \pm 0.01$ to $0.43 \pm 0.02 \mu \mathrm{g} / \mathrm{g})$ and $\mathrm{Zn}(8.20 \pm 0.01$ to $35.08 \pm 0.02 \mu \mathrm{g} / \mathrm{g})$. Both the contamination index and enrichment factor results indicated that all the soil samples were contaminated with Cd while a few sites showed Cu contamination. The mobility potential of the metals in the soil sample decreased in the order: $\mathrm{Mn}>\mathrm{Al}$ $>\mathrm{Zn}>\mathrm{Cd}>\mathrm{Cu}>\mathrm{Pb}$ (West) and $\mathrm{Cd}>\mathrm{Al}>\mathrm{Pb}>\mathrm{Zn}>\mathrm{Mn}>\mathrm{Cu}$ (East). The study revealed that the soil around the metal recycling factory is contaminated with heavy metals, and if left unmonitored and controlled could lead to serious environmental risk in the future.
\end{abstract}

Indexing terms/Keywords:Industrial impacts, Heavy metals, Speciation, Health risk, Environmental pollution.

\section{Academic Discipline And Sub-Disciplines}

Analytical/Environmental Chemistry

\section{SUBJECT CLASSIFICATION}

Heavy Metals Speciation in Soil

\section{TYPE (METHOD/APPROACH)}

Sample Collection and Digestion, Metal Speciation and Instrumental Analysis, Stastistical Treatment of Data

\section{Council for Innovative Research}

Peer Review Research Publishing System

\section{Journal:Journal of Advances in Chemistry}

Vol. 7, No. 1

editor@cirworld.com

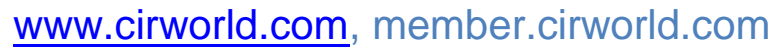




\subsection{INTRODUCTION}

Over time, environmental pollution by heavy metals from a metal recycling industry can become a very important source of contamination of soils, air and water within the vicinity of the industry. Metal scraps used as raw materials, deposited around the factory and the processing of these scraps into refined metals are capable of causing environmental degradation which have many adverse effects on human health, agricultural productivity and the natural ecosystem. It has been reported that accumulation of arsenic, cadmium, chromium, and nickel are carcinogenic and through inhalation over extended time period may cause serious health risks [1].

Sources of metals input into the soils mainly include natural occurrence derived from weathering of rock and anthropogenic sources, which according to Turpeinen, 2002 [2], can be divided into five major groups including (1) Metalliferous mining and smelting (As, Cd, Pb and $\mathrm{Hg}$ ); (2) Industry (As, Cd, Co, Cu, Hg, Ni, and Zn); (3) Atmospheric deposition (As, Cd, Cr, Cu, Pb, Hg and Ur); (4) Agriculture (As, Cd, Cu, Pb, Se, Ur and Zn); and (5) Waste disposal (As, $\mathrm{Cd}, \mathrm{Cr}, \mathrm{Cu}, \mathrm{Pb}, \mathrm{Hg}$, and $\mathrm{Zn})$.

The chemical behaviour of heavy metals in soils is controlled by a number of processes, including metal cation released from contamination source materials (e.g. fertilizer, sludge, smelter dust, slag), cation exchange and specific adsorption onto the surfaces of minerals and soil organic matter, and precipitation of secondary minerals [3]. Only soluble, exchangeable and chelated metal species in the soils are the labile fractions available for plants [4]. For this reason, the measurements of the total amount of heavy metals in the soils should be complemented with the measurements of the available fraction [3]. The knowledge of heavy metals accumulation in soil, the origin of these metals and their possible interactions with soil properties are priority objectives in many environmental monitoring. A metal recycling company situated around Fashina, Ile-Ife, Osun State Nigeria, engages in vigorous all year round metal scraps dumping and ironsteel processing activities. The heavy metal impacts of these activities should be regularly monitored along with the impact of other compounds. This is necessary because the entire area is surrounded by farmland where food crops are propagated.

The present study investigated the levels of heavy metals of surface soil samples around the sampling site with intent to determining the heavy metal pollution status of the soil in terms of the pollution index of each metal and their extent of bioavailability.

\subsection{MATERIALS AND METHOD}

\subsection{Description of the Study Area}

The study area, Ife Iron Steel (Nigeria) Limited (Figure 1), is located at the Western axis of lle-Ife along Ife/lbadan road at Fashina area, after toll gate through which two major heavily travelled roads enter the city. Ile-Ife lies at the intersection of roads from Ibadan to llesha and Ondo, between latitudes $07^{\circ} 29.574^{\prime}$ and $07^{\circ} 29.856^{\prime} \mathrm{N}$ and longitudes $004^{\circ} 28.404^{\prime}$ and $004^{\circ} 28.825^{\prime} \mathrm{E}$ with elevations between 241 and $262 \mathrm{~m}$ above sea level (Table 1 ). The average traffic density along these main trunk roads is 534 vehicles per hour [5]. Table 1 shows the zones and the geographical locations of the sampling points. The locations were mapped out using a Garmin 12 Channel GPS 310 as clearly indicated in Figure 1.

Table 1: Geographical Locations of the sampling sites

\begin{tabular}{llllr}
\hline Site description & Sampling & \multicolumn{2}{c}{ GPS Grid Coordinate } & Altitude \\
\hline & station code & Latitude (N) & Longitude (E) & (m) \\
\hline & & West & \\
\hline
\end{tabular}

\begin{tabular}{|c|c|c|c|c|}
\hline Factory /industry site yard & IB1 & $07^{U} 29.658$ & $004^{U} 28.572^{\prime}$ & 250 \\
\hline Fashina-forested area & IB2 & $07^{0} 29.777^{\prime}$ & $004^{0} 28.554^{\prime}$ & 254 \\
\hline Fashina-forested area & IB3 & $07^{0} 29.799$ & $004^{0} 28.504^{\prime}$ & 243 \\
\hline Fashina-forested area & IB4 & $07^{\cup} 29.817^{\prime}$ & $004^{0} 28.453^{\prime}$ & 245 \\
\hline Fashina-forested area & IB5 & $07^{\cup} 29.856$ & $004^{\circ} 28.404^{\prime}$ & 241 \\
\hline & \multicolumn{4}{|c|}{ East } \\
\hline
\end{tabular}


Factory /industry site yard

Company's staff residential area

Mini -market (Fashina)

Agricultural Farmland

Fashina-forested area
IF1

IF2

IF3

IF4

IF5 $07^{\circ} 29.574^{\prime}$

$004^{\circ} 28.646^{\prime}$

250

$07^{\circ} 29.705^{\prime}$

$004^{\circ} 28.674^{\prime}$

249

250

259

262

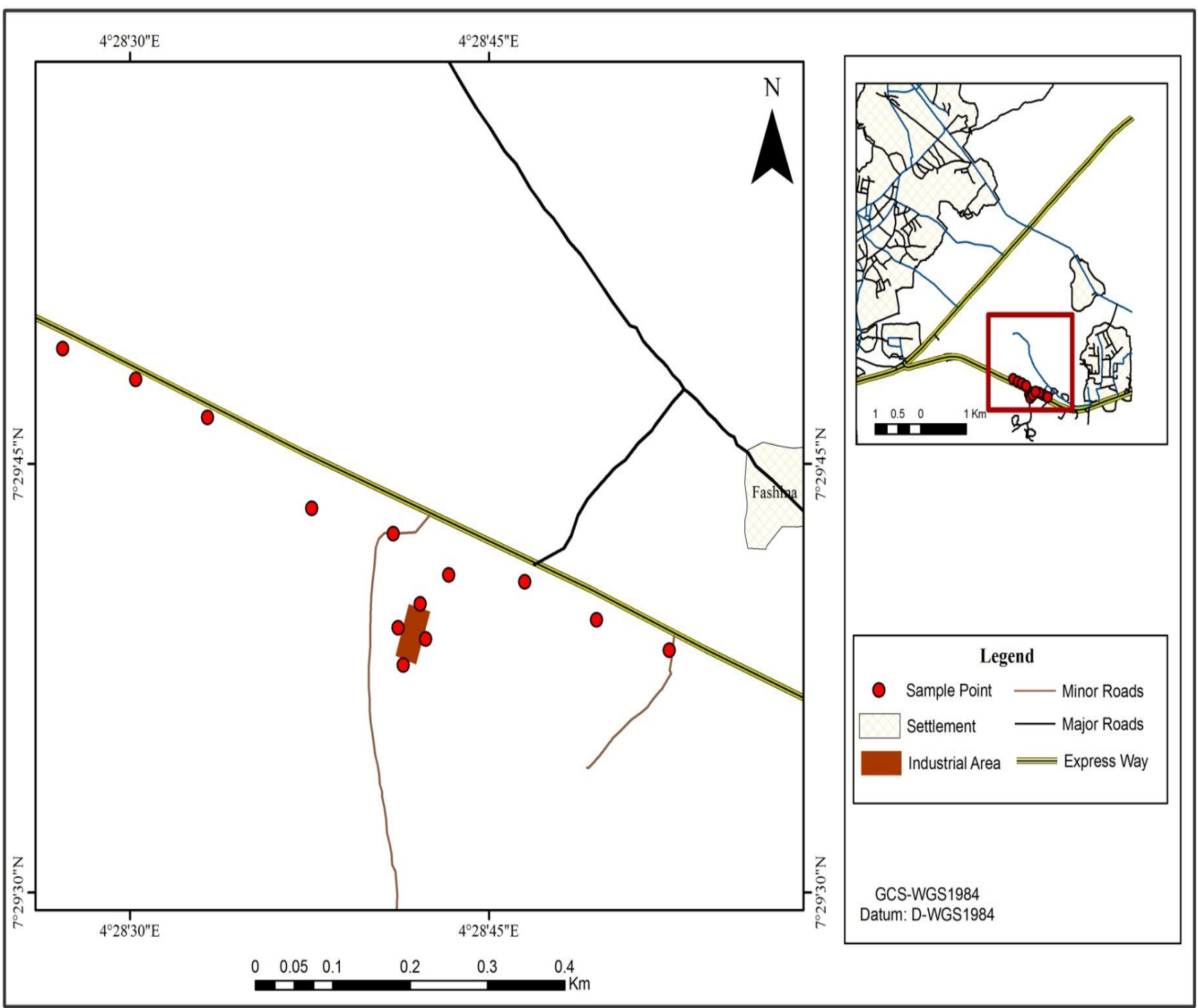

Figure 1: Map of the study area showing the sampling sites.

\subsection{Sampling and Pretreatment}

The sampling of the top soils was carried out at ten different locations around the factory site. The first five samples were collected at different sites on the West axis of the factory along Ibadan (IB) express-way, each at 100m interval from one another and designated as IB1 to IB5. Similarly, at the East axis of the factory along Ife town, a total of five sites were sampled, also at $100 \mathrm{~m}$ interval from one another and designated as IF1 to IF5. At each site, the topmost soil was sampledand each soil sample was made up of a composite of threesubsamplestakenfrom within a $1 \mathrm{~m} \times 1 \mathrm{~m}$ square using a plastic spoon. The collected composite samples were placed in a well- 
labeled, sealed polythene bags. After air-drying for two weeks, the soil samples were sieved to remove large materials, and later grounded with mortar and pestle into powdery form.

\subsection{Sterilization of Apparatus}

All glassware, polypropylene tubes and Teflon beakers were washed with soap, rinsed with tap water and distilled water. These apparatus were then soaked in $10 \% \mathrm{HNO}_{3}(\mathrm{v} / \mathrm{v})$ for $48 \mathrm{~h}[5]$, rewashed with soap and then rinsed thoroughly with doubly-distilled water.

\subsection{Reagents Used and Their Sources}

Reagents used included magnesium chloride, $\mathrm{MgCl}_{2}$ (Sigma Aldrich), glacial acetic acid (BDH Chemicals Ltd, Poole, England), NaOAC (BDH Chemicals Ltd, Poole, England), Hydroxylamine hydrochloride, $\mathrm{NH}_{2} \mathrm{OH} . \mathrm{HCl}$ (Chemicals Ltd, Poole, England), Nitric acid, $\mathrm{HNO}_{3}$ (BDH Chemicals Ltd, Poole, England), Hydrogen peroxide, $\mathrm{H}_{2} \mathrm{O}_{2}$ (Sigma Aldrich).

\subsection{Determination of the Total Metals}

Total metal determination was necessary in this study because there was no certified reference material with which to ascertain the accuracy and reliability of the procedures used in the speciation study. Hence, total metal determination was used as a basis for comparing the results of the sum of the sequential extraction fractions with what was obtained in a single step total metal determination.

Total metal determination was done by digesting an accurately weighed $(0.25-0.50 \mathrm{~g})$ soil sample using $\mathrm{HNO}_{3}$ and $\mathrm{HClO}_{4}$ by the method previously described by Oyekunleet al., 2011 [6]. The levels of $\mathrm{Al}, \mathrm{Cd}, \mathrm{Cu}, \mathrm{Mn}, \mathrm{Pb}$, and $\mathrm{Zn}$ were determined using the Flame Atomic Absorption Spectrophotometer (FAAS) Buck Scientific Model 205 by automatic interpolation with respect to the calibration graph. The determination was done in triplicate.

\subsection{Recovery Analysis}

Two $0.5 \mathrm{~g}$ portions each of properly dried and pulverized soil sample from the selected samples were used for recovery analysis. One portion was spiked with $10 \mathrm{~mL}$ of $1000 \mathrm{mg} / \mathrm{L}$ standard mixture of the heavy metal solutions while the other (control) portion was left unspiked. Both samples were carried through the digestion protocols as enumerated earlier. The resulting solutions were subjected to FAAS analysis. Calculation of percentage recovery (\% R) was done based on the relationship:

$$
\% R=\frac{\mathbf{A}-\mathbf{A} \mathbf{I}}{\mathbf{B}}
$$

where $A$ = heavy metal concentration in spiked soil sample; $A^{\prime}$ = heavy metal concentration in unspiked soil sample; and $B$ $=$ the amount of heavy metal used for spiking.

\subsection{Speciation Analysis}

One gram of each sample was weighed from the representative sample into the $50 \mathrm{~mL}$ polypropylene centrifuge tubes. Extractions were made through five steps $\left(F_{1}-F_{5}\right)$, the clear solution obtained from steps $\left(F_{1}-F_{4}\right)$ and the clear digested solution from step $\left(F_{5}\right)$ were accurately made to the appropriate volume with doubly-distilled water, and stored in plastic bottles. Concentrations of $\mathrm{Al}, \mathrm{Cd}, \mathrm{Cu}, \mathrm{Mg}, \mathrm{Pb}$ and $\mathrm{Zn}$ in the various solutions were determined by Atomic Absorption Spectroscopy. The extraction process for each fraction is described below.

\subsubsection{Exchangeable Fraction $\left(F_{1}\right)$}

The weighed sample was extracted at room temperature with $20 \mathrm{~mL} \mathrm{MgCl} 2(\mathrm{pH} 7)$ with continuous agitation for I h.

\subsubsection{Carbonate-Bound Fraction $\left(\mathrm{F}_{2}\right)$}

The residue from $F_{1}$ was treated at room temperature with $20 \mathrm{~mL} \mathrm{NaOAC}$ adjusted to $\mathrm{pH} 5$ with HOAC. Continuous agitation was maintained for $5 \mathrm{~h}$.

\subsubsection{Fe-Mn Oxides-Bound Fraction $\left(F_{3}\right)$}

The residue from $\mathrm{F}_{2}$ was extracted with $40 \mathrm{~mL} 0.04 \mathrm{M} \mathrm{NH} \mathrm{OH}_{2} \mathrm{HCl}$ in $25 \%(\mathrm{v} / \mathrm{v}) \mathrm{HOAC}$ at $96 \pm 1^{\circ} \mathrm{C}$ with occasional agitation for $5 \mathrm{~h}$.

\subsubsection{Bound to Organic Matter $\left(\mathrm{F}_{4}\right)$}

To the residue from $\mathrm{F}_{3}$ was added $7.5 \mathrm{~mL}$ of $0.2 \mathrm{M} \mathrm{HNO}_{3}$ and $12.5 \mathrm{~mL}$ of $30 \% \mathrm{H}_{2} \mathrm{O}_{2}$ adjusted to $\mathrm{pH} 2$ with $\mathrm{HNO}_{3}$. The mixture was heated to $85^{\circ} \mathrm{C}$ for $2 \mathrm{~h}$ with occasional agitation. A second $7.5 \mathrm{~mL}$ aliquot of $30 \% \mathrm{H}_{2} \mathrm{O}_{2}$ was added and heated further for $3 \mathrm{~h}$ at $85^{\circ} \mathrm{C}$ with intermittent agitation. After cooling, $12.5 \mathrm{~mL}$ of $3.2 \mathrm{M} \mathrm{NH}_{4} \mathrm{OAC}$ in $20 \%(\mathrm{v} / \mathrm{v}) \mathrm{HNO}_{3}$ was added to prevent the adsorption of extracted metals into the oxidized sediments and the mixture was diluted to $40 \mathrm{~mL}$. A continuous agitation for 30 minutes followed.

\subsubsection{Residual Fraction $\left(\mathrm{F}_{5}\right)$}

The residue from $\mathrm{F}_{4}$ was digested with $15 \mathrm{~mL}$ concentrated $\mathrm{HNO}_{3}$ and later refluxed for $1 \mathrm{~h}$. 


\subsection{Statistical Analysis}

For the interpretation of the geochemical data, the following statistical methods were used.

\subsubsection{Descriptive Statistics Used}

Descriptive statistics (mean, range, standard deviation) were performed in addition to correlation coefficient, contamination index, enrichment factor, andgeoaccumulation index. Geoaccumulation index were used to investigate the pollution status of the sites, while coefficient of variation was adopted to evaluate the spatial and temporal distribution patterns of the metals. Mobility factor was evaluated so as to determine the extent of bioavailability of the metals in the environment studied.

\subsubsection{Contamination Index}

The calculation of contamination index of metals in the soil samples was done using the relation below.

\section{Metal concentration in the soils Contamination index $(\mathrm{Cl})=\overline{\text { Background value of the metal }}$}

Average shale metal levels were taken as the background concentration [7-9]. The data obtained from the calculation of the contamination index were grouped into four grades as follows: $0-0.99=$ uncontaminated; $1.0-1.19=$ moderately to highly contaminated; $1.2-1.99$ = highly contaminated; 2.0 - 3.5 = very highly contaminated [10].

\subsubsection{Determination of Enrichment Factor (EF).}

Enrichment factor analysis is a method used to differentiate between the metals originating from anthropogenic activities and those from natural processes to assess the degree of anthropogenic influence [11]. It is calculated using the relationship:

$$
\mathrm{EF}=\frac{\left(C_{x} / C_{A 1}\right)_{\text {sample }}}{\left(C_{x} / C_{A 1}\right)_{\text {background }}}
$$

where $\left(C_{X} / C_{A I}\right)$ sample is the ratio of concentration of metal $\left(C_{X}\right)$ to that of $A I\left(C_{A I}\right)$ in the soil sample and $\left(C_{x} / C_{A I}\right)$ background is the reference ratio in the background. The background values were taken from average Shale [7-9] and $\mathrm{Al}$ (the reference value being $8.0 \mu \mathrm{g} / \mathrm{g}$ ) was selected as the reference element, due to its crustal dominance and its high immobility [12]. Five contamination categories [11] are recognized on the basis of the enrichment factor as follows: EF < 2 is deficiency to minimal enrichment; EF $2-5$ is moderate enrichment; EF $5-20$ is significant enrichment; EF 20 - 40 is very high enrichment; and EF > 40 is extremely high enrichment.

An increase in the EF values implies that there is an increased contribution of metals from the anthropogenic sources [11]. However, since enrichment factor is calculated by comparing the ratio of the level of the metal of interest to the level of aluminium, and comparing that to the respective levels in the earth's crust, which ought to be representative of natural soils, an enrichment factor less than 10 may be considered to represent natural levels, while a value greater than 10, on the other hand, is considered to indicate contamination by that metal [13]. Average elemental concentration data of the upper continental crust were taken from Taylor and McLennan, 1985 [14].

\subsubsection{Determination of Geoaccumulation Index.}

The geoaccumulation index (I-geo) values were calculated for different metals as introduced by Muller, 1979 [8] as follow:

$$
I-g e o=\log _{2}\left(\mathrm{C}_{\mathrm{n}} / 1.5 \mathrm{~B}_{\mathrm{n}}\right)
$$

where $C_{n}$ is the measured concentration of the heavy metal ' $n$ ' in the sample; $B_{n}$ is the geochemical background value of element ' $n$ '; and 1.5 is the background matrix correction factor due to lithogenic effects. Huu et al., 2010 [15] proposed seven grades or classes of the geoaccumulation index presented in Table 3.

\subsubsection{Mobility Factor (MF)}

The relationship adopted by Ogunfowowokan et al., 2009 [5], was used to determine the mobility factor of the metals. This relationship is:

$$
\mathrm{MF}=\frac{\mathbf{F 1}+\mathbf{F} 2}{\mathbf{F} 1+\mathbf{F} 2+\mathbf{F} 3+\mathbf{F} 4} \times 100
$$




\subsubsection{Coefficient of Variation (CV)}

CV was calculated using the relationship:

$$
\mathrm{CV}=\frac{\text { s. } \mathbf{d} .}{\bar{x}} \times 100
$$

wheres.d = standard deviation, $\bar{x}=$ mean.

\subsubsection{Correlation Coefficients}

The correlation coefficients $(r)$ for the samples were also calculated.

\subsection{RESULTS AND DISCUSSION}

\subsection{Validation of Analytical Procedures Adopted.}

The reliability of the analytical procedures adopted in this study was tested in terms of sensitivity, recovery, and accuracy. Table 2 shows the values for the calibration curve and percentage recovery (\%R) for the heavy metals. Under the experimental conditions used, the standard calibration curves obtained showed high linearity level with $r^{2}$ values between 0.9356 and 0.9895 . With recoveries of heavy metals in soil ranging from $79.61 \pm 7.73 \%$ to $98.25 \pm 3.45 \%$, these values were adjudged acceptable since they showed that precision was even better than the generally accepted $10 \%$ RSD level.

\subsection{Total Heavy Metals in the Soil Samples}

In Table 3, the total concentration of the heavy metals in the soil samples is presented and compared with the "average shale" concentration, which is considered as a "geogenic background" adopted as background concentration for soil [7-9]. This result is not significantly different at $p \leq 0.05$ from the mean total of the metals in the different fractions obtained for the speciation study summarized in Table 6 , thus further validating the precision and accuracy of the analytical procedures employed in this study.

Table 2: Calibration curve and percentage recovery $(\% \mathrm{R})$ for the heavy metals.

\begin{tabular}{|c|c|c|c|c|}
\hline Heavy metals & $\begin{array}{l}\text { Calibration curve } \\
\qquad r^{2}\end{array}$ & $\begin{array}{l}\text { Amount spiked } \\
\qquad(\mu \mathrm{g} / \mathrm{g})\end{array}$ & $\begin{array}{l}\text { Amount recovered } \\
\qquad(\mu \mathrm{g} / \mathrm{g})\end{array}$ & $\% \mathbf{R}$ \\
\hline Al & 0.9356 & 10 & 9.615 & $96.15 \pm 3.96$ \\
\hline $\mathrm{Cd}$ & 0.9725 & 10 & 8.923 & $89.23 \pm 0.93$ \\
\hline $\mathrm{Cu}$ & 0.9895 & 10 & 9.825 & $98.25 \pm 3.45$ \\
\hline $\mathrm{Mn}$ & 0.9633 & 10 & 7.961 & $79.61 \pm 7.73$ \\
\hline $\mathrm{Pb}$ & 0.9671 & 10 & 8.653 & $86.53 \pm 2.84$ \\
\hline $\mathrm{Zn}$ & 0.9819 & 10 & 9.351 & $93.51 \pm 2.10$ \\
\hline
\end{tabular}


Table 3: Total heavy metals in the soil samples of the study area

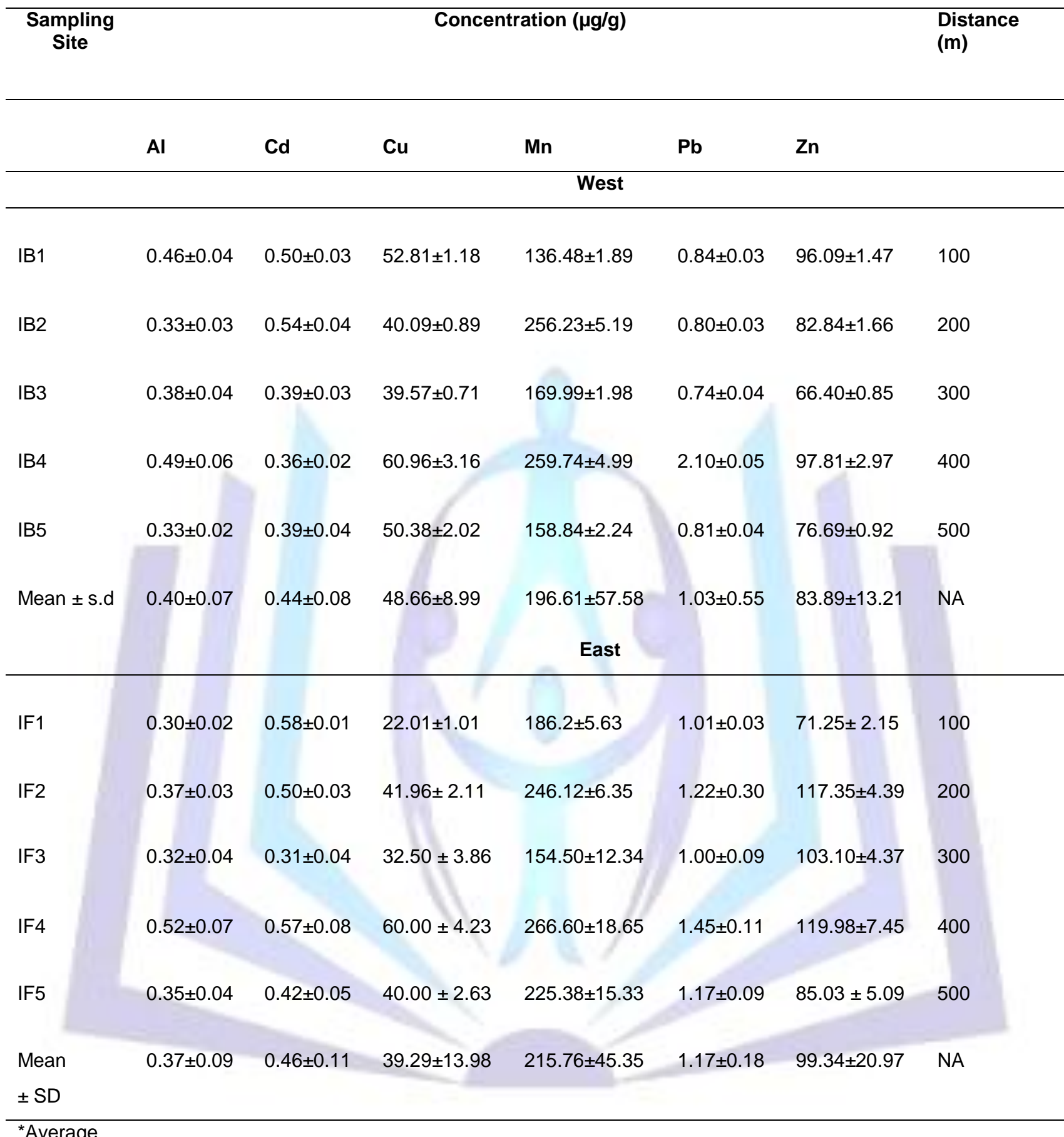

${ }^{*}$ Average

Shale

$8 \quad 0.3$

45

850

20

95 NA

*Background levels of metals in shales/rock(Source: Turekian and Wedepohl, 1961; Muller, 1979; Singh, 2001). NA: Not available

From Table 3, the mean concentration of the metals ranged from $0.40 \pm 0.07$ to $196.61 \pm 57.58 \mu \mathrm{g} / \mathrm{g}$ (West axis) and 0.37 \pm 0.09 to $215.76 \pm 45.35 \mu \mathrm{g} / \mathrm{g}$ (East axis). The average abundance of trace metals in the soil was of the order $\mathrm{Mn}>\mathrm{Zn}>$ $\mathrm{Cu}>\mathrm{Pb}>\mathrm{Cd}>\mathrm{Al}$. The result indicated that $\mathrm{Al}$ had the lowest concentration while $\mathrm{Mn}$ had the highest concentration for all the sites analysed. Aluminium levels $(0.30-0.50 \mu \mathrm{g} / \mathrm{g})$ in all the soil samples were lower than the $8.0 \mu \mathrm{g} / \mathrm{g}$ set as its natural background level in soil, whileCd in the soil samples $(0.31-0.58 \mu \mathrm{g} / \mathrm{g})$ exceeded the natural background level of $0.3 \mu \mathrm{g} / \mathrm{g}$ for soil [7-9]. Similarly, the highest levels of $\mathrm{Mn}(266.60 \mu \mathrm{g} / \mathrm{g})$ and $\mathrm{Pb}(2.10 \mu \mathrm{g} / \mathrm{g})$ were lower compared with their respective 850 and $20 \mu \mathrm{g} / \mathrm{g}$ natural background levels in soils [7-9]. The levels of $\mathrm{Cu}$ and $\mathrm{Zn}$ were generally higher than the reference limit of 45 and $95 \mu \mathrm{g} / \mathrm{g}$ respectively except in few sites where the levels of the metals were lower. 
The implication of this result is that while $\mathrm{Al}, \mathrm{Mn}$ and $\mathrm{Pb}$ concentration in the soil might not pose immediate significant environmental risk to either plants or animals around the factory, absorption of $\mathrm{Cd}, \mathrm{Cu}$ and $\mathrm{Zn}$ through plant, or their transportation through surface runoff and percolation to the underground water, streams and rivers which are the main source of domestic activities to people around the factory site could constitute an insidious health problems, especially if metal recycling activities continue without putting in place measures to curtail negative impacts on other environmental matrix. Apparently, the lateritic clay or clayey sand nature of the soil of the study area would enhance the accumulation of these metals since clayey soil has very high retention ability. According to Adepelumiet al., 2001 [16], the bedrock geology of the area is primarily igneous rock with four sub-surface layers of lateritic clay, clayey sand/sand, weathered/fractured bedrock, and fresh bedrock.

In general, the highest concentrations of the metals were observed at sites IB4 and IF4, both of which were cultivated agricultural farmlands as at the time of this study. The high metal concentrations could be due to anthropogenic activities from agricultural practices. For example, at IF4, evidences of past and fresh mechanical soil clearing and burrowing, applications of fertilizer, animal manures, pesticides and insecticides, harvesting and packaging of the farm produce were noted while this study was in progress. These human activities are capable of introducing trace metals to the soil [17]. It was reported that high concentrations of $\mathrm{Mn}, \mathrm{Zn}$ and $\mathrm{Pb}$ in soils is indicative of $\mathrm{Pb}$ being the primary anthropogenically derived pollutant trace metal in a given soil environment [18]. Wear of tyre and brake linings might have also contributed to the $\mathrm{Mn}$ concentrations obtained in the present study since the factory site is close to a heavily plied road.

Pig and poultry manures often contain high concentrations of $\mathrm{Cu}$ and $\mathrm{Zn}$ because $\mathrm{Cu}$ is normally supplied as an additive to achieve improvement of food conversion, and $\mathrm{Zn}$ is also added to the diets to counteract possible toxicity caused by the high addition of $\mathrm{Cu}$ [19]. Local commercial compost, refuse compost, and chicken manure also contained substantial amounts of trace metals [20]. The widespread and repeated applications of these materials could, therefore, be one of the reasons for the elevated $\mathrm{Cu}$ and $\mathrm{Zn}$ levels in the agricultural soil at site IF4.

The levels of the heavy metals in soils obtained in this study are compared with those of other related studies (Table 4), and also with local and international set standards (Table 5). In Table 4, it can be seen that the levels of Pb (0.74-2.10 $\mu^{-1}$ ) were lower than the $146-1620 \mathrm{\mu gg}^{-1}$ reported for soils of contaminated battery and iron smelting industrial areas of Southern Nigeria [21], or that of $9.8-136.1 \mathrm{\mu gg}^{-1}$ reported for the urban soils of Osogbo [22]. It is also lower compared with $15.0-650.0 \mu^{-1}$ and $12-882 \mu^{-1}$ reported for urban soils of Ibadan and Abakaliki respectively [18, 23], and much lower than the values 261-2296 $\mu^{-1}{ }^{-1}$ reported for top soils of London, United Kingdom. The mean levels of Pb obtained in this work were also lower than those reported for urban soils of other countries (Table 4). The reasons for the higher levels of lead reported for other cities and countries compared to the soil in the present study are likely due to intensive and massive urbanization, concentration of industries and higher automobile exhaust levels due to higher traffic volume. Ile-Ife is an ancient town with little or no industrialization [5]. However, the advent of the metal recycling industry barely two years ago at Fashina area where the present study was carried out, marked the commencement of what could be referred to as serious industrial activities in the town. Thus concentration of these heavy metals may increase in the future due to more industries and prolong years of operation.

The range of values of $\mathrm{Mn}\left(136.48-266.60 \mu \mathrm{g} \mathrm{g}^{-1}\right)$ obtained in this study was lower than the 336-1815 $\mu \mathrm{g} \mathrm{g}{ }^{-1} \mathrm{reported} \mathrm{in}$ Spanish soil [24]. The values were, however, higher than those of $\mathrm{Pb}, \mathrm{Cd}, \mathrm{Al}$ and $\mathrm{Cu}$ probably because automotive sources such as wear and tear of tires, lubricating oils and corrosion of brake lining of several trucks used to transport raw materials and finished product in and out of the factory contributed more 
Table 4: Soil metal level $\left(\mu \mathrm{g} \mathrm{g}^{-1}\right)$ obtained from other cities, compared with the present study

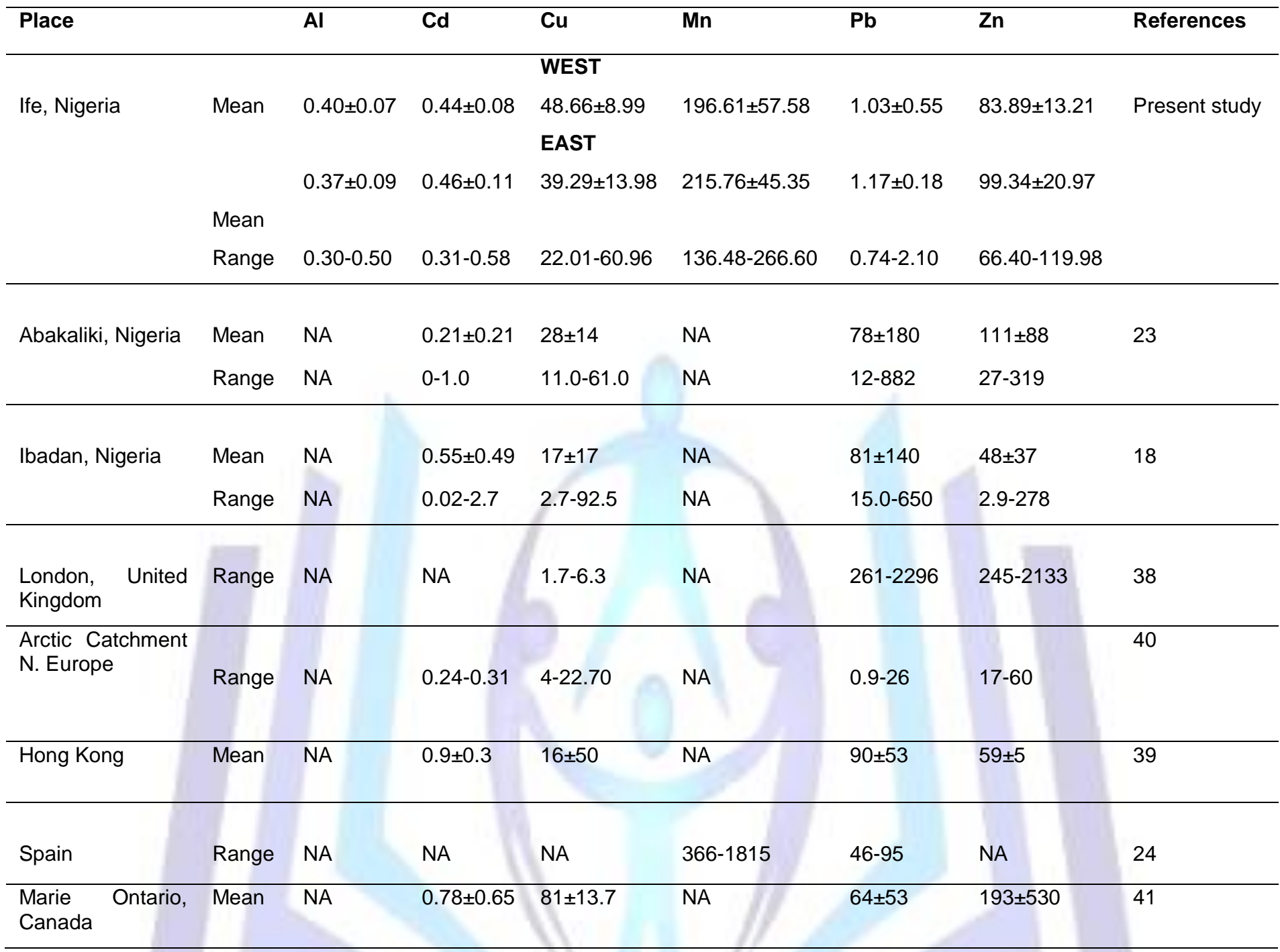

${ }^{*}$ NA: Not available, W: West, E: East

Mn to the soil environment of the study area. Generally, in this type of industry (iron, smelter, and metallurgical industries), high concentrations of $\mathrm{Pb}, \mathrm{Zn}, \mathrm{Mn}$, and $\mathrm{Cr}$ are frequently detected in the soil samples analyzed as typified by the levels ( $\mathrm{mg} \mathrm{kg}^{-1}$ ) of $\mathrm{Mn}(652), \mathrm{Pb}(85), \mathrm{Zn}(92)$, and $\mathrm{Cu}$ (47) found in soils surrounding the mining and smelting areas in Tharsis, Spain [25].

The mean levels of all the elements determined in this speciation study were either lower than or closely comparable to the stipulated background levels of heavy metals in soils worldwide [26, 27], except for the Department of Petroleum Resources that stipulated lower values of 35 and $36 \mu \mathrm{g} \mathrm{g}^{-1}$ for $\mathrm{Zn}$ and Cu respectively [28]. Thus, all the elements determined in this study were either lower than or closely comparable to the set standards for heavy metals in soils worldwide 
Table 5: A comparison of soil trace metal content $\left(\mu \mathrm{g} \mathrm{g}^{-1}\right.$ or $\mathrm{mg} \mathrm{kg}^{-1}$ ) in the present study with that of local and international set standards

\begin{tabular}{|c|c|c|c|c|c|c|c|}
\hline $\begin{array}{l}\text { Trace } \\
\text { metal }\end{array}$ & $\begin{array}{l}\text { Range conc. in the } \\
\text { present study }\end{array}$ & $\begin{array}{l}\text { Permissible } \\
\text { limit in India }\end{array}$ & $\begin{array}{l}\text { Stipulated } \\
\text { concentration in } \\
\text { Denmark }\end{array}$ & $\begin{array}{l}\text { SEPA limit } \\
\text { in China }\end{array}$ & $\begin{array}{l}\text { FEPA } \\
(1999) \\
\text { guideline }\end{array}$ & $\begin{array}{l}\text { D.P.R. } \\
\text { Limitvalue(2000) }\end{array}$ & $\begin{array}{l}\text { WHO } \\
(1999)\end{array}$ \\
\hline $\mathrm{Pb}$ & $0.74-2.10$ & $250-500$ & 40 & 350 & $250-500$ & 85 & 70 \\
\hline $\mathrm{Cd}$ & $0.31-0.58$ & $3-6$ & 5 & 0.6 & $<1.0$ & 0.8 & 10 \\
\hline $\mathrm{Zn}$ & $66.40-119.98$ & $300-600$ & 200 & 300 & $300-600$ & 35 & 200 \\
\hline $\mathrm{Cu}$ & $22.01-60.96$ & $135-270$ & NA & 100 & NA & 36 & NA \\
\hline $\mathrm{Mn}$ & $136.48-266.60$ & NA & NA & NA & NA & NA & NA \\
\hline $\mathrm{Al}$ & $0.30-0.50$ & NA & NA & NA & NA & NA & NA \\
\hline
\end{tabular}

Sources:State Environmental Protection Agency (SEPA), America, (1995) [27]; Federal Environmental Protection Agency (FEPA), Nigeria (1999) [42]; Department of Petroleum Resources (DPR), Nigeria (2000) [28]; Oyeku, 2002 [44]; Ezigbo, 2011 [45]; NA = Not available.

Despite the low concentration of the heavy metals in top soil investigated in this work, their long-term accumulation and distribution through food chain and water bodies around the study area can be potential future health risk. For example, uptake of Al through food, by inhalation and skin contact can lead to CNS damage, dementia, loss of memory, listlessness, and severe trembling [29]. The USEPA has defined a soil Pb value of $1000 \mathrm{ppm}$ as the level that correlates with the critical blood lead level of $7 \mu \mathrm{g} \mathrm{dL}^{-1}$ in children [30,31]. The highest lead level recorded in this study is $2.10 \mu \mathrm{g} \mathrm{g}$ or $2.10 \mathrm{ppm}$ which is far less than the USEPA $1000 \mathrm{ppm}$ level. However, the present levels call for closer and continuous monitoring in the soil.

Excessive exposure of humans to $\mathrm{Mn}$ and its compounds could lead to severe pathological disorders of the central nervous system that may manifest as a permanent crippling neurological disorder of the extra pyramidal system similar to Parkinson's disease, reproductive and immune system dysfunctions, nephritis, testicular damage, pancreatitis, lung disease, hepatic damage, aggressiveness, hallucinations, disturbances of the libido and improper coordination [32, 33].

Although humans can handle proportionally large concentrations of $\mathrm{Zn}$, too much $\mathrm{Zn}$ can still cause imminent health problems, such as stomach cramps, skin irritations, vomiting, nausea and anaemia. Very high levels of zinc can damage the pancreas and disturb the protein metabolism, and cause arteriosclerosis. Extensive exposure to zinc chloride can cause respiratory disorders and only a limited number of plants have a chance of survival on zinc-rich soils [29]. That is why there is not much plant diversity near zinc-disposing factories.

According to Olukayode, 2005 [34], inhalation of Cd accounts for 15-50\% of absorption through the respiratory system while $2-7 \%$ of ingested cadmium is absorbed in the gastrointestinal system. Hence, the target organs (the liver, placenta, kidneys, lungs, brain and bones) are at risk and the inhalers stand a chance of severe respiratory health conditions. People living in cadmium-contaminated areas have higher urinary cadmium concentrations [35].

\subsection{Heavy Metal Levels in the Various Soil Fractions}

Table 6 presents the mean levels of the metals in the different soil fractions. The mean levels of $\mathrm{Al}$ ranged from $0.03 \pm 0.01$ $\mu \mathrm{g} \mathrm{g}^{-1}$ to $0.14 \pm 0.02 \mu \mathrm{g} \mathrm{g}^{-1}$ in both West and East axes of the factory. The mean Cd levels ranged between $0.03 \pm 0.01$ and $0.16 \pm 0.03 \mu \mathrm{g} \mathrm{g}^{-1}$ (West axis) and $0.05 \pm 0.02$ to $0.16 \pm 0.04 \mathrm{\mu g} \mathrm{g}^{-1}$ (East axis) of the factory. The result indicated that Cd also 
predominantly resided in the residual fraction. The presence of $\mathrm{Cd}$ in the soil samples could partly be as a result of anthropogenic input from the industrial processing activities in which metal scraps, automobile parts and metallic wires are constantly used as raw materials. Since the factory started operations not too long ago, the particulate metal deposits from industrial activities might form part of the residual fraction. High levels of $\mathrm{Cd}$ in the residual fraction could also be attributed to the high retention ability of the mineral's crystal structure, such as with detrital silicates, and oxides in which most of the $\mathrm{Cd}$ was locked up and can only be extracted under hard acidic conditions. Thus, the present levels of $\mathrm{Cd}$ in the soil sample at both East and West axis of the metal recycling factory may not constitute immediate serious health hazards to plants and animals.

Table 6. Mean levels of metals $(\mu \mathrm{g} / \mathrm{g})$ in the various fractions of soil samples across the sites

\begin{tabular}{|c|c|c|c|c|c|c|c|}
\hline \multirow[b]{2}{*}{ Metal } & \multicolumn{7}{|c|}{ Concentration of metals in the fractions } \\
\hline & Site $^{*}$ & F1 & F2 & F3 & F4 & F5 & Total \\
\hline \multirow[t]{2}{*}{ Al } & IB1 - IB5 & $0.09 \pm 0.01$ & $0.07 \pm 0.02$ & $0.05 \pm 0.02$ & $0.03 \pm 0.01$ & $0.14 \pm 0.02$ & $0.39 \pm 0.07$ \\
\hline & IF1 - IF5 & $0.09 \pm 0.02$ & $0.06 \pm 0.01$ & $0.04 \pm 0.01$ & $0.03 \pm 0.01$ & $0.14 \pm 0.04$ & $0.36 \pm 0.09$ \\
\hline \multirow[t]{2}{*}{ Cd } & IB1 - IB5 & $0.10 \pm 0.03$ & $0.06 \pm 0.02$ & $0.05 \pm 0.02$ & $0.03 \pm 0.01$ & $0.16 \pm 0.03$ & $0.41 \pm 0.08$ \\
\hline & IF1 - IF5 & $0.12 \pm 0.03$ & $0.09 \pm 0.03$ & $0.05 \pm 0.02$ & $0.05 \pm 0.02$ & $0.16 \pm 0.04$ & $0.46 \pm 0.11$ \\
\hline \multirow[t]{2}{*}{$\mathrm{Cu}$} & IB1 - IB5 & $9.90 \pm 2.00$ & $9.05 \pm 1.96$ & $7.82 \pm 1.56$ & $6.67 \pm 1.42$ & $15.18 \pm 2.15$ & $48.62 \pm 8.99$ \\
\hline & IF1 - IF5 & $8.28 \pm 3.17$ & $6.69 \pm 2.54$ & $5.79 \pm 2.68$ & $4.88 \pm 1.99$ & $13.01 \pm 3.55$ & $38.65 \pm 13.51$ \\
\hline \multirow[t]{2}{*}{ Mn } & IB1 - IB5 & $45.48 \pm 7.47$ & $39.19 \pm 8.65$ & $32.89 \pm 7.80$ & $27.47 \pm 5.89$ & $50.55 \pm 3.21$ & $195.19 \pm 58.11$ \\
\hline & IF1 - IF5 & $44.93 \pm 8.63$ & $38.39 \pm 9.96$ & $32.54 \pm 8.26$ & $27.09 \pm 7.17$ & $70.64 \pm 13.17$ & $213.59 \pm 44.98$ \\
\hline \multirow[t]{2}{*}{$\mathbf{P b}$} & IB1 - IB5 & $0.20 \pm 0.03$ & $0.15 \pm 0.02$ & $0.29 \pm 0.47$ & $0.05 \pm 0.03$ & $0.32 \pm 0.05$ & $1.02 \pm 0.55$ \\
\hline & IF1 - IF5 & $0.27 \pm 0.04$ & $0.22 \pm 0.04$ & $0.17 \pm 0.04$ & $0.13 \pm 0.04$ & $0.36 \pm 0.05$ & $1.13 \pm 0.21$ \\
\hline \multirow[t]{2}{*}{$\mathbf{Z n}$} & IB1 - IB5 & $19.18 \pm 2.95$ & $14.88 \pm 2.56$ & $12.09 \pm 2.01$ & $10.97 \pm 1.90$ & $26.76 \pm 4.83$ & $84.49 \pm 13.94$ \\
\hline & IF1 - IF5 & $21.32 \pm 5.84$ & $19.01 \pm 5.24$ & $15.91 \pm 3.55$ & $13.18 \pm 2.31$ & $28.55 \pm 4.84$ & $97.96 \pm 20.65$ \\
\hline
\end{tabular}

${ }^{*} \mathrm{IB} 1-\mathrm{IB} 5$ = Sites within the West axis; IF1 - IF5 = Sites within the East axis

However, measures should be put in place to forestall future effects resulting from long-term accumulation of trace metals in soil.

Levels of $\mathrm{Cu}$ in the various fractions ranged from $6.67 \pm 1.42$ to $15.18 \pm 2.15 \mu \mathrm{g} \mathrm{g}^{-1}$, and $4.88 \pm 1.99$ to $13.01 \pm 3.55 \mu \mathrm{g} \mathrm{g}{ }^{-1}$ in the soil samples of the West and the East axes respectively. From the result, most $\mathrm{Cu}$ in the soil samples were present in the residual fraction, followed by the exchangeable and carbonate bound fractions, indicating its tendency to be relatively bioavailable for plants uptake. However, its higher occurrence in the residual fraction reduces its associated hazards to man and plants since the greater part of the metal are strongly bound in this form and generally reduces its bioavailability.

For $\mathrm{Mn}$, the levels in the various soil fractions values ranged from $27.47 \pm 5.89$ to $50.55 \pm 3.21 \mu \mathrm{g} \mathrm{g}{ }^{-1}$, and $27.09 \pm 7.17$ to $70.64 \pm 13.17 \mathrm{\mu g} \mathrm{g}^{-1}$ for the samples obtained from the factor's West and the East axis respectively. The West axis of the factory was characterized by sparse human settlement. This might be a reason for less anthropogenic introduction of Mn into the soil.

Levels of $\mathrm{Pb}$ in the various soil fractions of the soils ranged from $0.05 \pm 0.03$ to $0.32 \pm 0.05 \mu \mathrm{g} \mathrm{g}^{-1}$ (West axis) and $0.13 \pm 0.04$ to $0.36 \pm 0.05 \mathrm{\mu g} \mathrm{g}^{-1}$ (East axis). Unlike $\mathrm{Cu}, \mathrm{Mn}$ and $\mathrm{Zn}, \mathrm{Pb}$ and Cd occurred at very low concentrations in all the soil samples around the factory site investigated. The current $\mathrm{Pb}$ levels obtained in this study may not pose any serious environmental risk to man, plants and animals around the study area since a larger proportion of the metal was associated with the residual fraction in all the soils analysed and might not readily dissolve in surface waters, or percolate ground waters in solubilized forms, or bioaccumulate in plants.

In the case of $\mathrm{Zn}$, its levels in the various soil fractions ranging from $10.97 \pm 1.90$ to $26.76 \pm 4.83 \mu \mathrm{g} \mathrm{g}{ }^{-1}$ (West axis), and $13.18 \pm 2.31$ to $28.55 \pm 4.84 \mu^{-1} g^{-1}$ (East axis) were considered relatively high. Its elevated levels in the soil of the study area are ascribed to anthropogenic sources including input from the iron and steel industry as $\mathrm{Zn}$ is used in galvanizing and plating of metals, deposition of metals scraps, tear and wear of automobile parts and metallic wires that are used as raw materials in the iron and steel industry, and so on.

The general trend was that the least levels of the metals were associated with the organic matter fraction while the highest levels were found in the residual fraction. Mean metal levels in the various soil fractions followed the trend: residual > 
exchangeable $>$ bound to carbonate $>$ Fe-Mn oxides bound $>$ organic matter. The elevated levels of the metals in the residual fraction could be as a result of a large proportion of the soil coming from the background aluminosilicate rock weathering characteristic of natural soil deposit of the study area. It is noteworthy however, that residual fraction (F5) contains metals mainly in form of silicates, cements and passivated oxides. Therefore their inactive oxides might only be extracted under hard acidic conditions [36]. Thus, the result obtained in this study suggested, to a large extent, that the presence of metals in the soils of the study area could be attributed to either their natural presence in the soil-forming parent rocks, or transportation and redistribution arising from surface runoff.

Future weathering and additions from the factory might result in more of the metals becoming environmentally available. It is important to note that higher levels of $\mathrm{Cd}(0.46 \pm 0.11 \mu \mathrm{g} / \mathrm{g}), \mathrm{Mn}(213.59 \pm 44.98 \mu \mathrm{g} / \mathrm{g}), \mathrm{Pb}(1.13 \pm 0.21 \mu \mathrm{g} / \mathrm{g})$, and $\mathrm{Zn}$ $(97.96 \pm 20.65 \mu \mathrm{g} / \mathrm{g})$ resided in the East axis soil samples of the factory as against $\mathrm{Cd}(0.41 \pm 0.08 \mu \mathrm{g} / \mathrm{g}), \mathrm{Mn}(195.99 \pm$ $58.11 \mu \mathrm{g} / \mathrm{g}), \mathrm{Pb}(1.02 \pm 0.55 \mu \mathrm{g} / \mathrm{g})$, and $\mathrm{Zn}(84.49 \pm 13.94 \mu \mathrm{g} / \mathrm{g})$ levels in the West axis. This observation could be due to greater wind deposition of particles towards the East axis of the factory in addition to wear and tear of tires, lubricating oils and corrosion of brake lining of several factory trucks in and around the factory area at the East axis compared to the West axis of the factory.

For metals like $\mathrm{Cd}, \mathrm{Cu}$ and $\mathrm{Zn}$ the values reported in this work were, however, more elevated than soil reference or background levels, a phenomenon traceable to metals incursion into the soil due to anthropogenic activities in the area. The anthropogenic sources could be due to effluents discharged from the metal recycling industry in the area, or application of agrochemicals on agricultural land within the vicinity of the industry.

Exchangeable and carbonate-bound fractions (F1 and F2) are the labile forms and most of the metals in the present study occurred at low concentrations in these fractions. Apparently, future environmental changes that could be caused by release of gaseous anhydrides from the industrial processes could lead to acid rain capable of rendering more metals solubilized and more available. Hence, it is imperative to monitor and control, as much as possible, from the onset the amounts of such gases that could be released into the atmosphere.

\subsection{Contamination Index (Cl)}

Based on the contamination index ratings: $0-0.99=$ uncontaminated; $1.0-1.19=$ moderately to highly contaminated; 1.2 $-1.99=$ highly contaminated; $2.0-3.5=$ very highly contaminated [10], it could be stated from the results in Table 7 that the soil samples from sites IB1-IB5 were highly contaminated with $\mathrm{Cd}$ (Cl: $1.13-1.73)$; with

Table 7: Contamination index of the metals in the soil samples at sites around the iron and steel company

\begin{tabular}{|c|c|c|c|c|c|c|}
\hline Site & Al & Cd & $\mathrm{Cu}$ & Mn & $\mathbf{P b}$ & Zn \\
\hline IB1 & 0.06 & 1.63 & 1.17 & 0.16 & 0.04 & 1.01 \\
\hline IB2 & 0.04 & 1.73 & 0.89 & 0.30 & 0.04 & 0.87 \\
\hline IB3 & 0.05 & 1.20 & 0.88 & 0.19 & 0.04 & 0.69 \\
\hline IB4 & 0.06 & 1.13 & 1.35 & 0.30 & 0.10 & 1.03 \\
\hline IB5 & 0.04 & 1.20 & 1.12 & 0.19 & 0.04 & 0.81 \\
\hline Mean \pm s.d. & $0.05 \pm 0.01$ & $1.38 \pm 0.28$ & $1.08 \pm 0.20$ & $0.23 \pm 0.07$ & $0.05 \pm 0.03$ & $0.88 \pm 0.14$ \\
\hline IF1 & 0.04 & 1.93 & 0.49 & 0.22 & 0.05 & 0.75 \\
\hline IF2 & 0.05 & 1.67 & 0.93 & 0.29 & 0.06 & 1.24 \\
\hline IF3 & 0.04 & 1.03 & 0.72 & 0.18 & 0.05 & 1.09 \\
\hline IF4 & 0.07 & 1.90 & 1.33 & 0.31 & 0.07 & 1.26 \\
\hline IF5 & 0.04 & 1.40 & 0.89 & 0.27 & 0.06 & 0.90 \\
\hline Mean \pm s.d. & $0.05 \pm 0.01$ & $1.59 \pm 0.38$ & $0.87 \pm 0.31$ & $0.25 \pm 0.05$ & $0.06 \pm 0.01$ & $1.05 \pm 0.22$ \\
\hline
\end{tabular}

respect to $\mathrm{Cu}$, site IB4 was highly contaminated $(\mathrm{Cl}: 1.35)$, and sites IB1 and IB5 fell within moderately to highly contaminated rating. Sites IB1 and IB4 fell into the category of moderately to highly contaminated with respect to $\mathrm{Zn}$ while none of the site was contaminated with Al. In a similar way, sites IF1 - IF5 were not contaminated with Al, but were either moderately or highly contaminated with $\mathrm{Cd}(\mathrm{Cl}$ : $1.03-1.93)$; IF4 was highly contaminated with $\mathrm{Cu}(\mathrm{Cl}$ : 1.33$)$, while the sites were either not contaminated or had moderate to high $\mathrm{Zn}$ contamination.

\subsection{Enrichment Factor (EF)}

Figure 2 presents the enrichment factors $(E F)$ values for the metals in the soil sample. Following the classifications: EF $<2$ = deficiency to minimal enrichment; EF $2-5$ = moderate enrichment; EF $5-20$ = significant enrichment; EF $20-40=$ very high enrichment; EF $>40$ = extremely high enrichment [11], samples from the West axis of the factory showed a very high enrichment in Cd (EF: 19.29 - 43.33), with the highest EF for the metal recorded at site IB2. All the sampling sites 
also showed significant enrichment in Zn (EF: 15.11 - 20.15) and Cu (EF: 18.98 - 27.91). Mn showed a moderate enrichment (EF: $2.83-7.51)$ while $\mathrm{Pb}$ in the entire soil sample showed a deficiency to minimal enrichment $(E F<2)$.

It is evident from Figure 2 that the enrichment factors for $\mathrm{Cu}, \mathrm{Zn}$ and $\mathrm{Mn}$ in the soil samples from the East axis of the factory were greater than 10 which implies a significant enrichment of these metals in the soil. Therefore, apart from the normal geochemical sources of these metals, it is possible that anthropogenic activities such as metal recycling processes, fossil fuel combustion, traffic emissions, and tear and wear of brake lining materials had started playing noticeable addition to the soil enrichment of these metals.
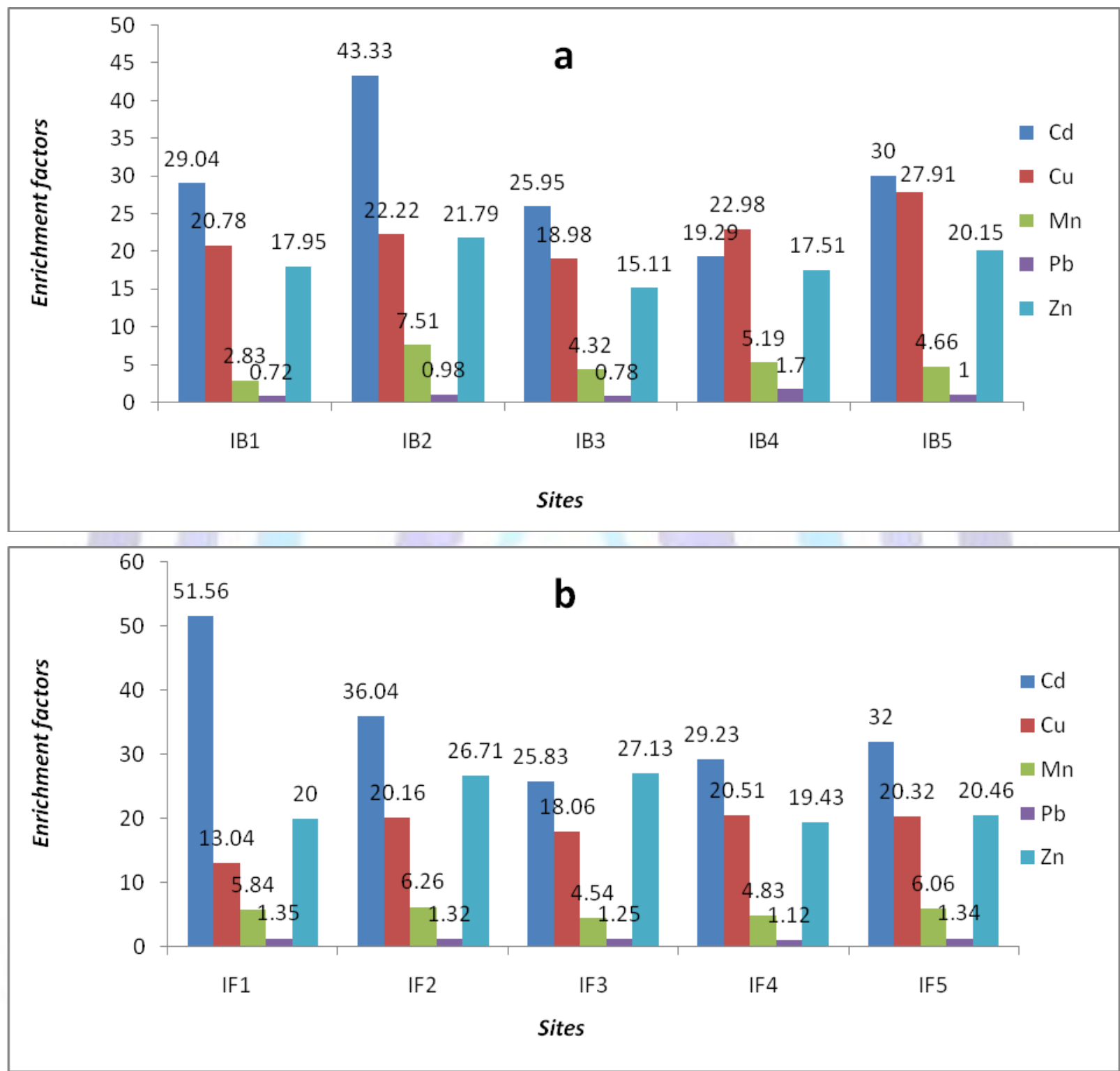

Figure 2: Enrichment factors (EF) for the metals in the soils at sites (a) West axis and (b) East axis of the iron and steel company.

\subsection{Geo-accumulation Index (I-geo)}

The result of geo-accumulation index $(I-g e o)$ in the soil samples is shown graphically in Figure 3. The negative values of $\mathrm{Al}, \mathrm{Mn}$, and $\mathrm{Pb}$ according to contamination classification of geoaccumulation factor as used by Huu et al., 2010 [15] showed that the soil was not polluted by these metals. The I-geo values of $\mathrm{Cd}, \mathrm{Cu}$ and $\mathrm{Zn}$ in the soil samples were less than 1 but greater than zero indicating that the soil from the sites were moderately polluted by $\mathrm{Cd}, \mathrm{Cu}$ and $\mathrm{Zn}$. A similar trend was obtained for the l-geo values of the soil samples from the East axis of the factory. Values of the I-geo factor are not readily comparable with those of the enrichment factor because I-geo calculation involves a logarithmic function and a background multiplication factor of 1.5 [37]. 


\subsection{Pearson's Correlation Coefficient Analysis.}

Pearson's correlation coefficient analysis was conducted to evaluate the association of the elements in the soil. From Table 8, there existed a high significant correlation for the $\mathrm{Al} / \mathrm{Cd}, \mathrm{Al} / \mathrm{Cu}, \mathrm{Cd} / \mathrm{Cu}, \mathrm{Al} / \mathrm{Zn}, \mathrm{Cd} / \mathrm{Zn}, \mathrm{Cu} / \mathrm{Zn}$ and $\mathrm{Cu} / \mathrm{Pb}$ pairs indicating that these metals originated from similar background natural or anthropogenic sources such as weathering of underlying rock deposits, transportation by wind or surface runoff, decomposition of alloys and other human activities. A negative correlation existed between $\mathrm{Pb}$ and $\mathrm{Mn}$, while $\mathrm{Pb}$ does not correlate strongly with $\mathrm{Zn}$ and $\mathrm{Cd}$ which partly indicated that $\mathrm{Pb}$ deposition was from a different source.

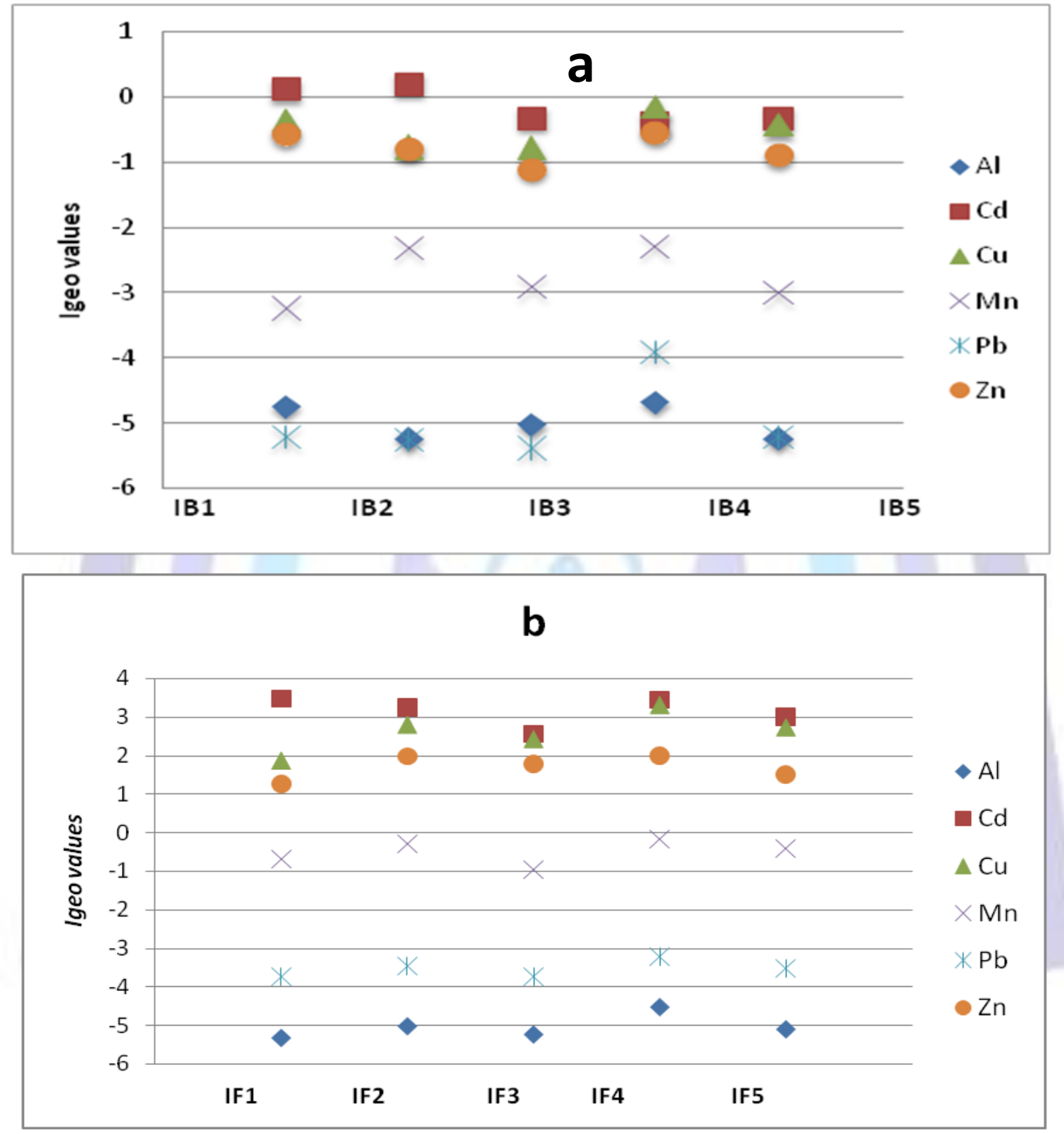

Figure 3: Geo-accumulation index (l-geo) for the metals in the soils at sites (a) West axis and (b) East axis of the iron and steel company. 
Table 8. Correlation coefficients matrix between trace metal concentrations of soil samples

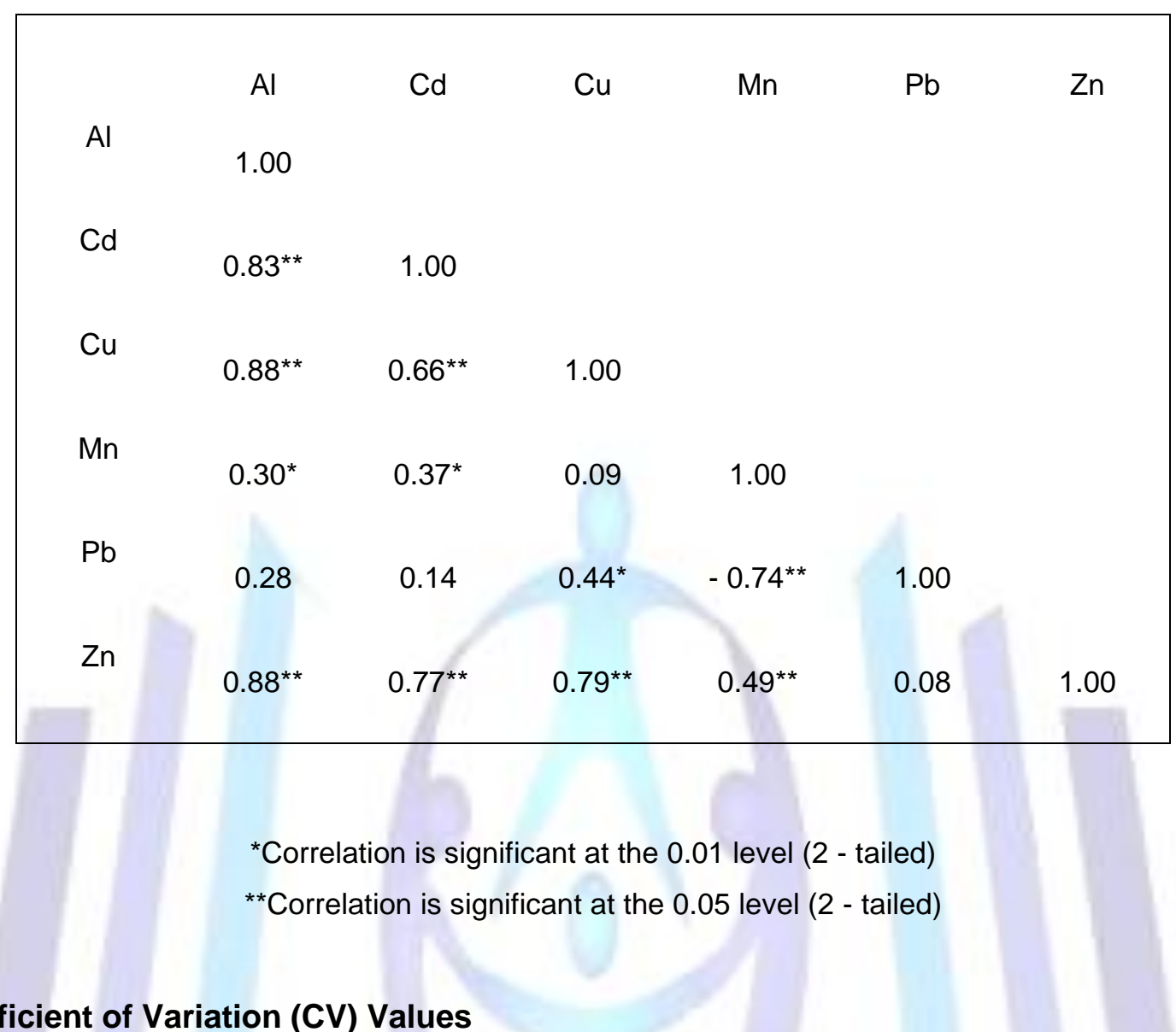

Coefficient of variation (CV) is used in this study to illustrate the temporal distribution pattern of the metals within the study area. From Figure 4, it can be seen that towards the West axis of the factory, $\mathrm{Mn}, \mathrm{Cu}$ and $\mathrm{Zn}$ were similarly distributed while between IB1 and IB3, Al, Cd and Pb also shared closely related distribution patterns. However, the distribution of Pb manifested wide variations implying that the manner of $\mathrm{Pb}$ addition into the soil environment was greatly different from those of the other metals as from IB3 to IB5. On the East axis, Pb was also widely distributed than the other metals while $\mathrm{Cd}$ and $\mathrm{Al}$ on one hand, and $\mathrm{Zn}$ and $\mathrm{Mn}$ on the other hand, had closely related distribution pattern. Generally, the CV values showed that for most of the metals, the anthropogenic inputs followed a similar pattern and were still minimal as at the time of this study. 

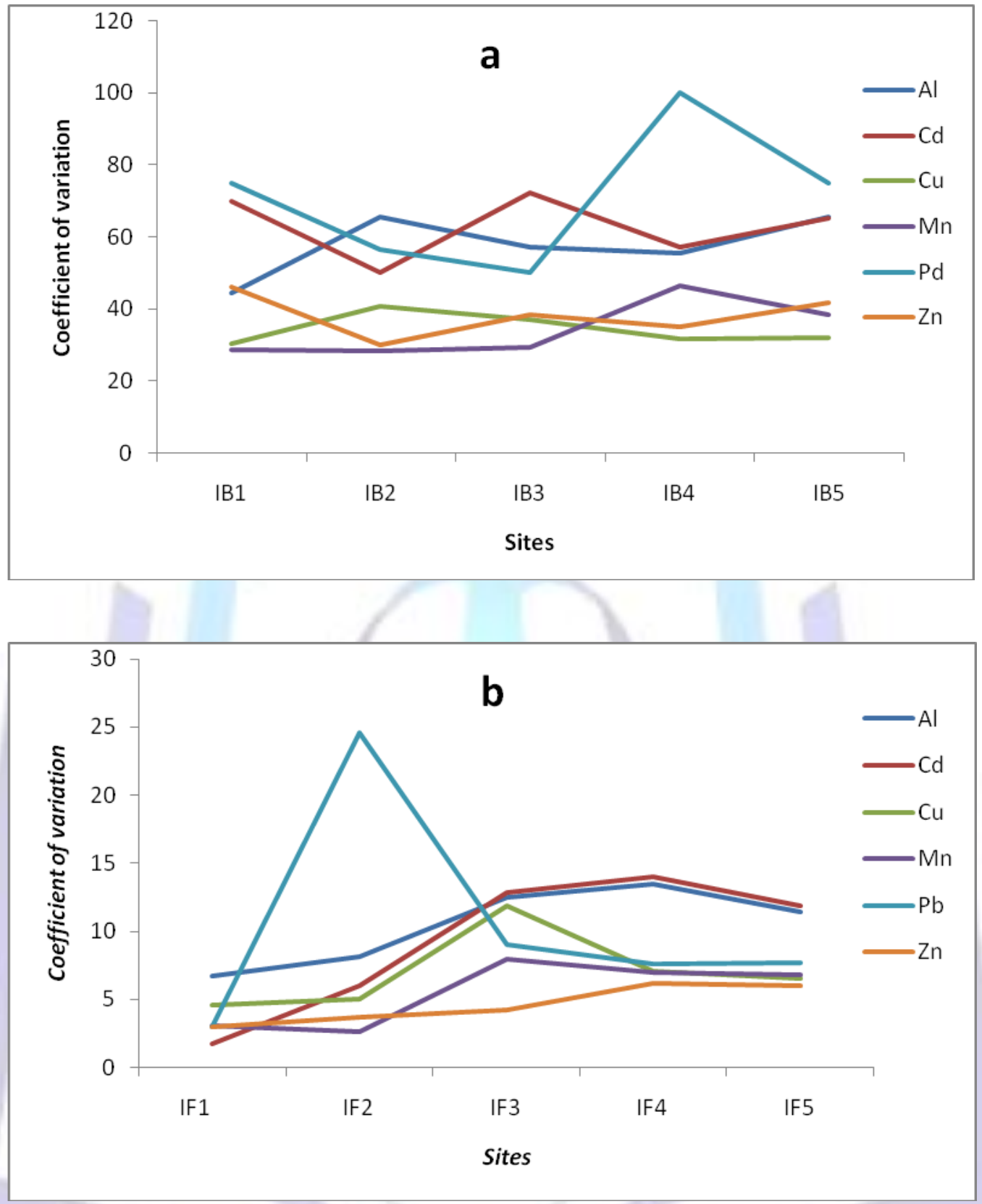

Figure 4: Coefficient of variation (CV) for the metals in the soils at sites (a) West axis and (b) East axis of the iron and steel company.

\subsection{Mobility Factor (MF)}

The mobility of heavy metals in soil environments depends essentially on the soil composition and properties, metal species and other environmental factors such as the weather conditions and precipitation pattern in that environment. From Figure 5, the mobility factor (MF) for the metals gave the order: $\mathrm{Mn}>\mathrm{Al}>\mathrm{Zn}>\mathrm{Cd}>\mathrm{Cu}>\mathrm{Pb}(\mathrm{West}$ axis) and $\mathrm{Cd}>\mathrm{Al}>\mathrm{Pb}>\mathrm{Zn}>\mathrm{Mn}>\mathrm{Cu}$ (East axis). At the West axis, the highest MF value was recorded for Mn at sites IB1 and IB5 while Pb had the lowest MF value at site IB4. This could be as a result of soil type at IB4 which is clayish and have high binding capacity for $\mathrm{Pb}$. The high $\mathrm{MF}$ value recorded for $\mathrm{Mn}$ in this study is in agreement with the study of Ogunfowokan et al., 2009 [5] where $\mathrm{Mn}$ was reported to be more bioavailable than $\mathrm{Pb}$ in the soil of lle-lfe. On the other hand, the mobility behaviour of $\mathrm{Al}, \mathrm{Cd}, \mathrm{Cu}$ and $\mathrm{Zn}$ followed a similar trend and these metals might exhibit similar leaching behaviours into other environmental matrices such as soil, surface water and underground water.

At the East axis, Cd has the highest MF (50.91\%) at site IF1 (Factory yard) implying that Cd would be the most bioavailable metal readily leachable from the factory yard into the environmental aquatic and soil systems. Cadmium is a 
by-product of the mining and smelting of lead and zinc. It can also be found in soils because insecticides, fungicides, sludge, and commercial fertilizers that use $\mathrm{Cd}$ are used in agriculture. For all the metals on both axes of the factory, no one had a MF lower than 20. The future implication of this is that as manufacturing activities continue, these figures may keep mounting making the ecosystems within the vicinity of the factory more amenable to heavy metal impacts.
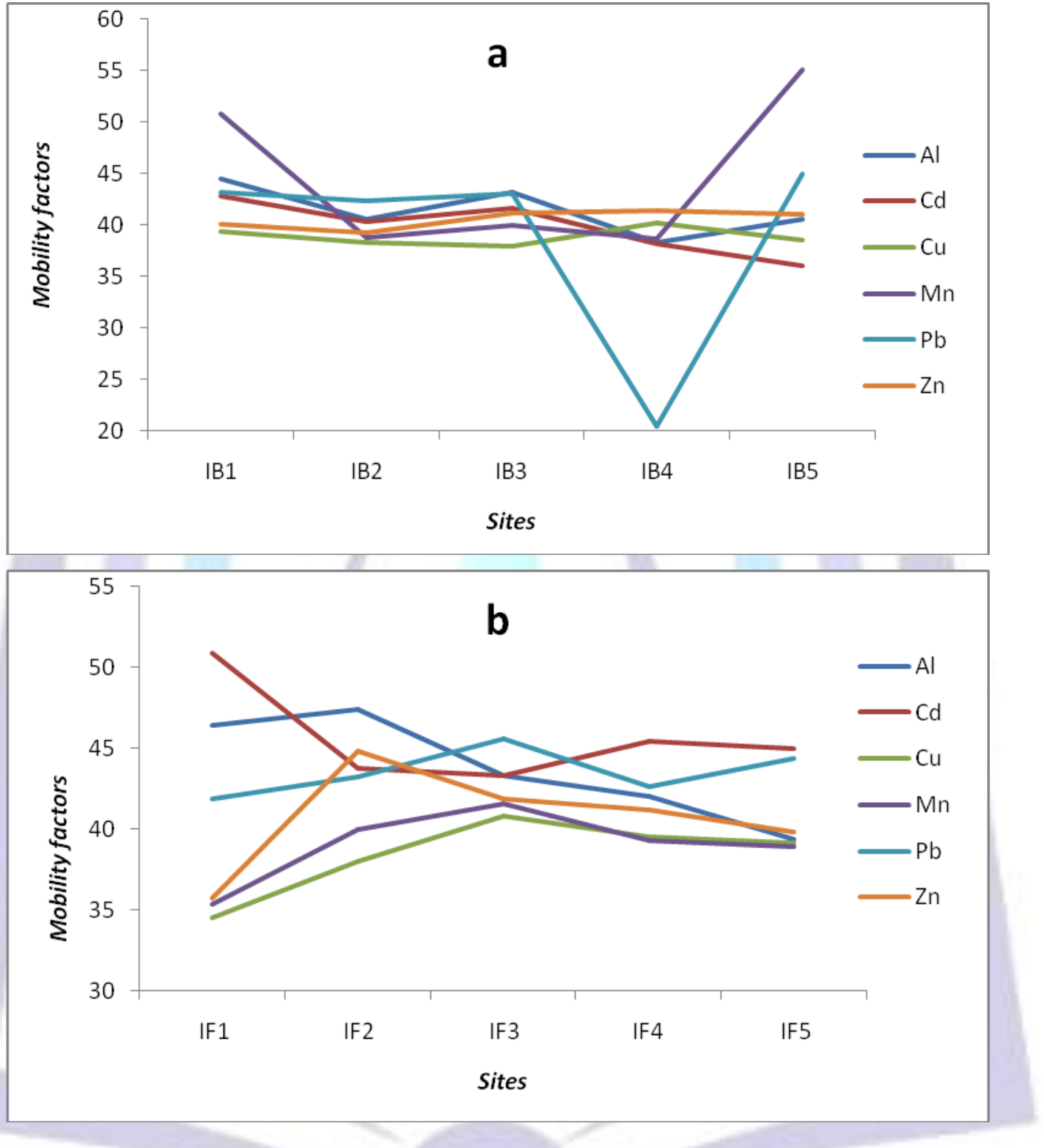

Figure 5: Mobility factor (MF) for the metals in the soils at sites (a) West axis and (b) East axis of the iron and steel company.

\subsection{CONCLUSION}

In this study, levels of $\mathrm{Al}, \mathrm{Cd}, \mathrm{Cu}, \mathrm{Mn}, \mathrm{Pb}$ and $\mathrm{Zn}$, and their species in soil samples of the study area showed that $\mathrm{Al}$ had the lowest concentration while $\mathrm{Mn}$ had the highest concentration in all the sites analysed. Cadmium was found at concentrations that were slightly above the background soil limits, a fact supported by the various pollution indices employed for the metals in the soils. Copper and Zinc were also found at concentrations above reference limit at some sites. The mean levels of the metals obtained in this work were however lower than those reported for urban soils of Nigeria and other countries. Speciation studies of the metals demonstrated that they occur largely in the residual fraction of the soil and therefore were not freely mobile or bioavailable in the environment. This speciation study indicated that at present, most of the metals could only pose minimal hazards to both plants and animals because of their higher percentage in the residual fraction within which metals are normally locked up and rendered nonbioavailable.

However, the levels at which some of the metals existed may pose serious environmental risk to plants, animals and people living around the study area in the nearest future. Thus, continuous monitoring and future studies of the area are 
necessary to ascertain long term effects of the industrial activities and its associated heavy metals pollution. It is also important to carry out studies on air and water bodies around the study area to determine the extent of the impact of the industrial processes on heavy metals pollution of these environmental matrices.

\section{ACKNOWLEDGEMENT}

The authors acknowledge ObafemiAwolowo University (OAU) Ile-Ife, Nigeria, for providing the research platform for this study.

\section{REFERENCES}

[1] Friberg, L., Nordberg, G. F. and Vouk, V. B. 1986. Handbook on the toxicology of metals, 2nd. Ed., (Elsevier Science and Technology), pp. 5-6.

[2] Turpeinen, R. 2002. Interactions between metals, microbes and plants - Bioremediation of arsenic and lead contaminated soils.

[3] Nastja, R., Tadej, D. S., Goran T. T. and Matej D. 2008. Geoenvironment 55, 444.

[4] Kabata, P.A. 1993. Applied Goechemistry 2, 3.

[5] Ogunfowokan, A.O., Oyekunle, J.A.O., Durosinmi, L.M., Akinjokun, A.I. and Gabriel O.D. 2009. Chem. Ecol. 25 , 405.

[6] Oyekunle, J.A.O., Ogunfowokan, A.O., Torto, N. and Akanni, M.S. 2011. Journal of International Environmental Application and Science 6, 483.

[7] Turekian, K.K. and Wedepohl, K.H. 1961. Geological Society American Bulletin 72, 175.

[8] Muller, G. 1979. VeranderungenSeittUmschan 79, 778.

[9] Singh, M. 2001. Environmental Geology 40, 664.

[10] Victor, A.A., Akinlolu, F.A. and Cheo, E.S. 2005. The Arabian Journal for Science and Engineering 31, 147.

[11] Sutherland, R.A. 2000. Environmental Geology39, 611.

[12] Mohiuddin, K.M., Zakir, H.M., Otomo, K., Sharmin, S. and Shikazono, N. 2010. Int. J. Environ Sci. Technol. 7,17.

[13] Idrees, F.A. 2009, Journal of Chemistry 4, 77.

[14] Taylor, S.R., McLennan, S.M. 1985. The Continental Crust: its Composition and Evolution, Blackwell Scientific Publications, Oxford.

[15] Huu, H.H., Rudy, S. and Damme, A.V. 2010. Geol. Belgica 13, 37.

[16] Adepelumi, A., Ako, B. and Ajayi, T. 2001. Hydrogeology Journal9, 611.

[17] Alloway, B.J. 1996. Heavy Metal in Soil, Halsted Press, John Wiley and Sons Inc., London, pp. 280 - 339.

[18] Onianwa, P.C. 2001. Soil and Sediment Contamination 10, 577.

[19] Cheung, Y. H. and Wong, M. H. 1983. Agricultural Wastes 5, 63.

[20] Wong, M.H. 1990. Biological Waste 31, 223.

[21] Olajire, A.A., Ayodele, E.T., Oyediran, G.O. and Oluyemi, E.A, Envir. Monit. Assess. 85, 135.

[22] Fakayode, S.O. and Olu-Owolabi, B.I. 2003, Envir. Geol. 44, 150.

[23] Chukwuma, C. Sr. 1996. Water Air Soil Pollut. 86, 13.

[24] Garcia, R. and Millan,E. 1998. Chemosphere 37,1615.

[25] Chopin, E.I.B. and Alloway, B.J. 2007. Science of The Total Environment 373, 488.

[26] Federal Environmental Protection Agency (FEPA), 1999. Guidelines and Standard for Environmental Pollution Control in Nigeria, pp. 200.

[27] State Environmental Protection Administration, SEPA, 1995. Environmental quality standard for soils, China. GB15618.

[28] Department of Petroleum Resources, DPR, 2000. Nigeria, Soil quality guidelines in industrial area, Vol. 1.

[29] Lenntech, B.V. 2011. "Chemical properties and environmental effect of Zinc" Water treatment Solution. http://www.lenntech.com/periodic/elements/zn.htm\#ixzz10XGHb3xg cited March 08, 2012.

[30] USEPA, 1994. Guidance Manual for the Integrated Exposure Uptake Biokinetic Model for Lead in Children. EPA/540/R-93/081. Office of Emergency and Remedial Response, Washington, D.C.

[31] Tsuji, J.S., and Serl, K.M. (1996). Environ. Geochem. Health 18, 25. 
[32] Keen, C.L. and Ziderberg-Cherr, S. 1993. Manganese, in Encyclopedia of Food Science, Food Technology and Nutrition, R. Macrae, R.K. Robinson, and M.J. Sadler, ed., Vol. 5, Academic Press, London, pp. 2863-2868.

[33] Lenntech, B.V. 2011b. Chemical properties and environmental effect of Manganese" Water treatment Solution. http://www.lenntech.com/periodic/elements/zn.htm\#ixzz10XGHb3xg cited August 09, 2012.

[34] Olukayode, A.O. 2005. Heavy metal speciation studies of agricultural soil of ObafemiAwolowo University, Ile-Ife, Nigeria, 'Unpublished B.Sc. Thesis'; Department of Chemistry, ObafemiAwolowo University, Ile-Ife, p. 11.

[35] World Health Organization (WHO), 1992. IPCS Environmental Health Criteria: Cadmium, WHO, Geneva.

[36] Feng, X.D., Dang, Z., Huang, W.L. and Yang, C. 2009. Int. J. Environ. Sci. Tech. 6, 337.

[37] Fagbote, E.O. and Olanipekun, E.O. 2010. Eurasian Journal of Scientific Research 5, 241.

[38] Ellis, J.B. and Revitt, D.M. 1982. Water Air Soil Pollut. 17, 87.

[39] Chen, T.B., Wong, J. W. C., Zhou, H. Y. and Wong, M.H. 1997. Environ. Pollut. 9661.

[40] Reimann, C., Boyd, R., de Caritat, P., Halleraker, J.H., Kashulina, G., Niskavaara H. and Bogatyrev, I. 1997. Environ. Pollut. 95, 45.

[41] Stone, M. and Marsalek, J. 1996. Water Air Soil Pollut. 87, 149.

[42] Federal Environmental Protection Agency, FEPA 1999. Guidelines and Standard for Environmental Pollution Control in Nigeria, pp. 200.

[43] World Health Organization, 1999. IPCS Environmental Health Criteria: Copper, WHO, Geneva.

[44] Oyeku, O.T. 2002. The Effect of Refuse-Dump on Soil and Underground Water in Ojota, Lagos Metropolis, 'Unpublished B. Tech. Thesis', Federal University of Technology, Akure, Nigeria. pp 44-50.

[45] Ezigbo, V.O. 2011. Journal of Basic Physical Research 2, 82. 